\title{
Perempuan Bali dalam Kontestasi Pemilu: Kuantitas vs Kualitas
}

\author{
I G.A.A. Dewi Sucitawathi', I Wayan Joniarta ${ }^{2}$ \\ 12Program Studi IImu Administrasi Negara \\ Fakultas Hukum dan IImu Sosial, Undiknas \\ Email:1iga_dewi@undiknas.ac.id; 2joniarta_12345@yahoo.com
}

\begin{abstract}
Women's political participation in the political stage has increased, one of which is due to the creation of the 2003 Election Law which regulates the quota of women legislative candidates at least 30 percent. The emergence of regulations that open wide avenues for women to take part in politics, in fact, is inversely proportional to the conditions of women cadres in Bali. In Bali, women who succeed in sitting in the district / city legislature can be counted by fingers. From the 2004 to 2014 elections, no more than 10 percent of Balinese women succeeded in gaining positions in the regional legislature. The number of Balinese women who participated was relatively large, but after voting (elections), only a few managed to win. So that this raises the phenomenon of Balinese female cadres being only used as a tool to fulfill the quota of political parties without being given the knowledge, motivation and fighting spirit to take careers seriously in the world of practical politics.
\end{abstract}

Keywords: political participation, women politician, political party, legislative candidates

\section{LATAR BELAKANG MASALAH}

Pasca-berakhirnya era Orde Baru, masyarakat Indonesia mulai merasakan udara kebebasan (freedom) baik pada bidang sosial, politik dan hukum. Kebebasan yang dimiliki oleh masyarakat Indonesia berwujud kebebasan dalam mengemukakan pendapat, kebebasan mengekspresikan ide/pemikiran, kebebasan memilih pemimpin tanpa unsur SARA (suku, agama, ras, antargolongan), serta kebebasan politik yang tidak selalu menjadi domain golongan laki-laki tetapi kebebasan politik yang melibatkan peran aktif golongan perempuan. Era reformasi yang saat ini dijalani Indonesia membuka seluas-luasnya partisipasi rakyat dalam proses pembangunan negara, salah satu konsep utama yang sering didengungkan oleh rakyat Indonesia adalah demokrasi. Salah satu unsur yang terkandung dalam konsep 'demokrasi' adalah keadilan (fairness), dan salah satu tolak ukur melihat kualitas demokrasi Indonesia dilihat dari proporsi laki-laki dan perempuan yang berimbang dalam kancah politik.

Pemerintah Indonesia membuktikan komitmennya dalam menjalani proses demokrasi, yaitu menjamin eksistensi dan keterlibatan aktif perempuan dalam kancah politik melalui 'peraturan perundang-undangan'. Ada dua produk UU yang secara tegas menekankan perlunya perempuan untuk diikut sertakan dalam politik, yaitu (Gerintya, 2017) dalam www.tirto.id:

a. UU No. 2 Tahun 2008: Aturan yang mewajibkan setiap partai politik menyertakan keterwakilan perempuan minimal 30 persen dalam pendirian maupun kepengurusan di tingkat pusat. 
b. UU No. 10 Tahun 2008: Aturan yang berisi partai politik baru dapat mengikuti Pemilu, apabila keterwakilan perempuan dalam kepengurusan partai politik tingkat pusat sudah memenuhi minimal 30 persen.

Kondisi Perempuan Indonesia yang terjun ke dunia politik pun memperlihatkan kondisi lebih baik. Berikut beberapa tabel yang menunjukkan kemajuan tingkat partisipasi politik perempuan di dunia, ASEAN, dan Indonesia:

\section{Tabel 1}

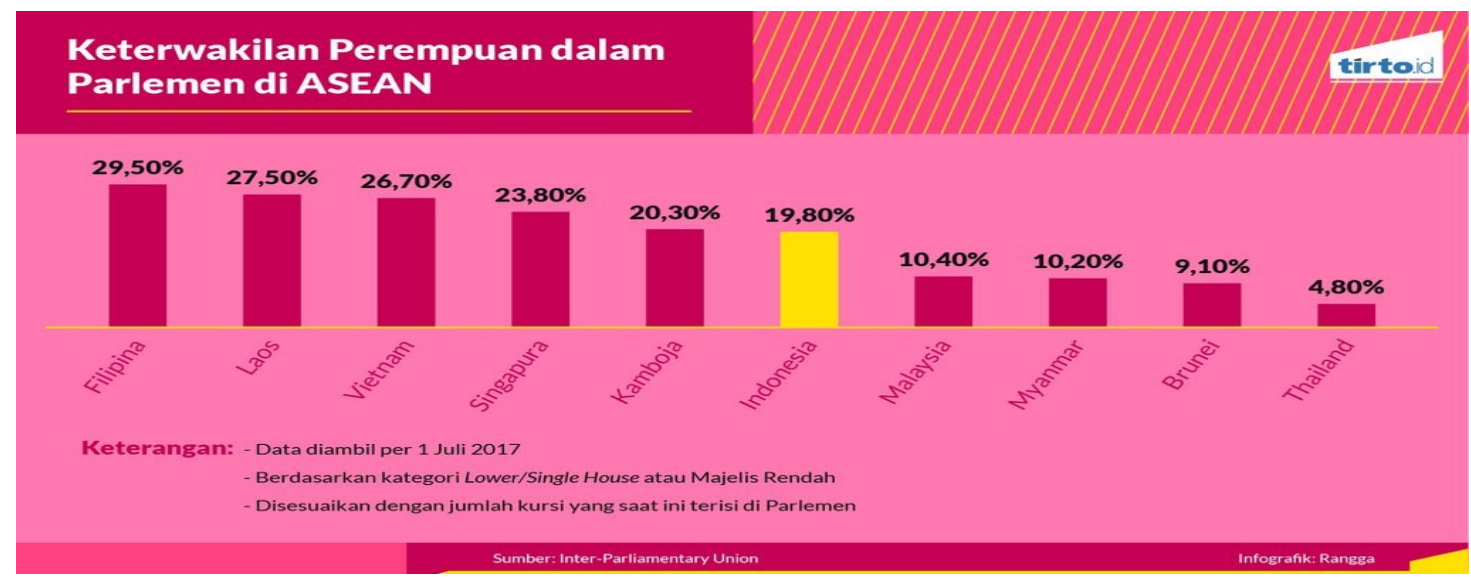

Tabel 2

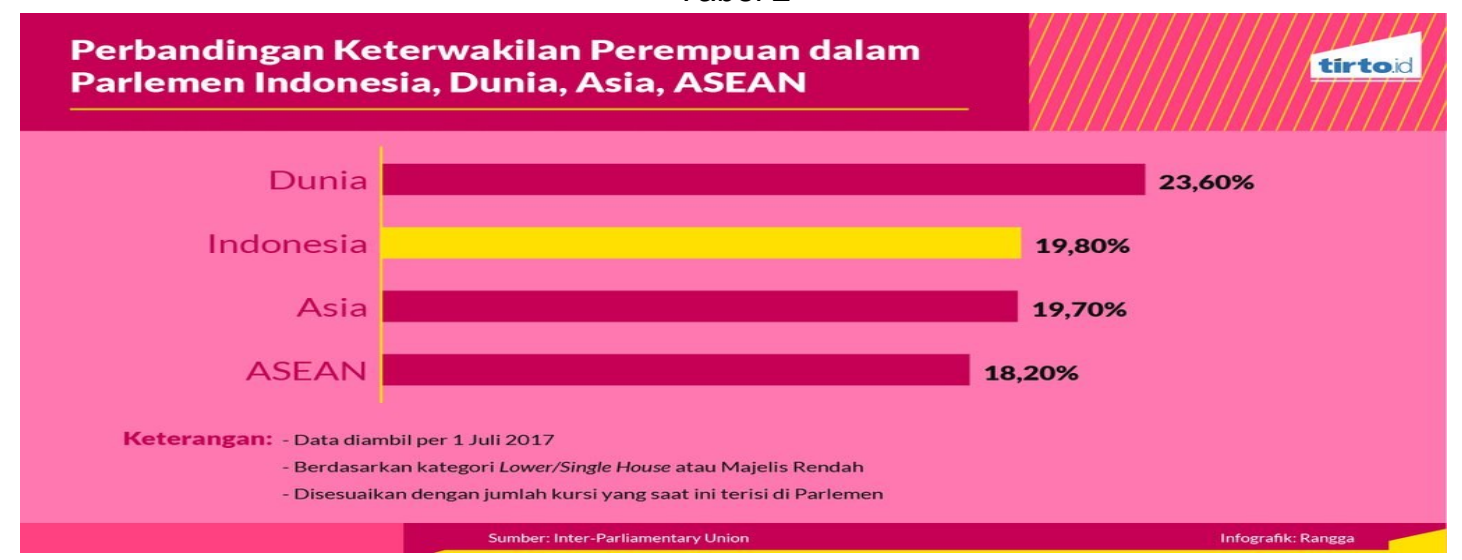

Tabel 3

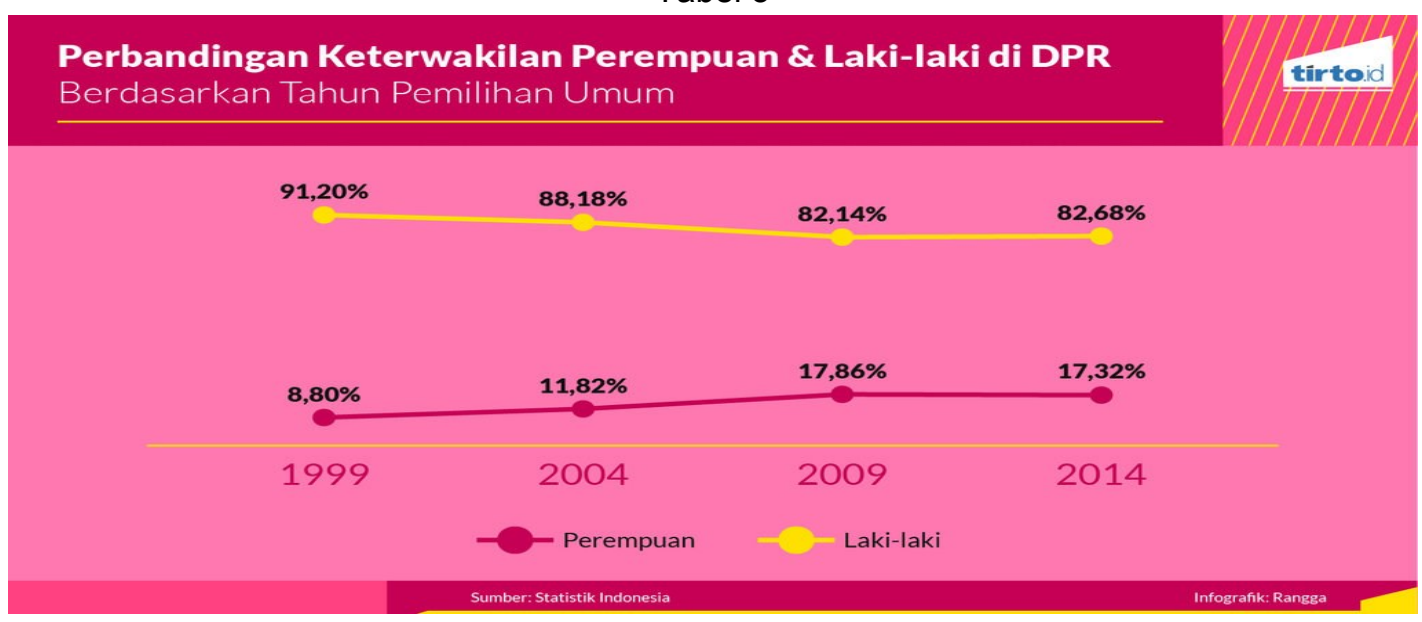


Tabel 4

\begin{tabular}{|c|c|c|c|c|c|}
\hline \multicolumn{5}{|c|}{$\begin{array}{l}\text { Jumlah Anggota DPR RI per Partai Politik } \\
\text { Berdasarkan Jenis Kelamin }\end{array}$} & \\
\hline & \multicolumn{2}{|c|}{ 2009-2014 } & \multicolumn{2}{|c|}{ 2014-2019 } & \\
\hline Nasdem & $\begin{array}{c}\text { Laki-laki } \\
\text { o }\end{array}$ & $\begin{array}{c}\text { Perempuan } \\
\text { o }\end{array}$ & $\begin{array}{c}\text { Laki-laki } \\
\quad 31\end{array}$ & $\begin{array}{c}\text { Perempuan } \\
4\end{array}$ & \\
\hline PKB & 21 & 7 & 37 & 10 & \\
\hline PKS & 54 & 3 & 39 & 1 & \\
\hline PDIP & 77 & 17 & 88 & 21 & \\
\hline Golkar & 88 & 18 & 75 & 16 & \\
\hline Gerindra & 22 & 4 & 62 & 11 & \\
\hline Demokrat & 113 & 35 & 48 & 13 & \\
\hline PAN & 39 & 7 & 40 & 9 & \\
\hline PPP & 33 & 5 & 29 & 10 & \\
\hline Hanura & 14 & 3 & 14 & 2 & \\
\hline
\end{tabular}

(Keterangan: Tabel 1,2,3,4 dikutip dari https://tirto.id/kuota-30-perempuan-di-parlemenbelum-pernah-tercapai-cv8q).

Dari tabel diatas bisa terlihat kondisi perempuan sudah jauh lebih baik dalam hal tingkat partisipasi (kuantitas), sedangkan pada kenyataannya permasalahan utama yang muncul adalah tidak banyak politisi perempuan yang memiliki kecapakan/kemampuan politik praktis (kualitas). Kondisi global, dunia, dan nasional ternyata tidak berbanding lurus dengan kenyataan di Bali. Seperti contoh Pemilukada 2014, calon anggota DPD RI yang memiliki kursi 4 orang, terdapat 41 orang calon, dan 2 diantaranya adalah 2 calon perempuan sebesar 4,9 persen, dan calon legislatif perempuan Bali yang berkiprah secara nasional masih sangat rendah sebesar 7,5 persen (Rahayu dalam Putri, 2019) dalam www.bali.idntimes.com. Selain itu pada Pemilukada 2014 dari beberapa calon yang berkompetisi ternyata anggota DPRD Kota Denpasar hanya diisi oleh satu orang perempuan yaitu Putu Metta dari Partai Golkar (2014-2019), dan DPRD Kota Denpasar periode 2009-2014 yaitu Sari Galung dari Partai PDI Perjuangan.

Berdasarkan data LSM Bali Sruti, perempuan Bali yang lolos menjadi anggota DPR RI tidak lebih dari 10 persen (Rahayu dalam Putri, 2019) dalam www.bali.idntimes.com. Partai Politik dalam hal ini terlihat hanya menjadikan perempuan sebagai alat untuk memenuhi kuota partai agar lolos seleksi Pemilu. Kondisi sama terjadi pada Pemilu 2019 ini, nama calon legislatif perempuan cukup banyak untuk pemilihan DPRD Provinsi Bali seperti PKB: 2 calon perempuan, Partai Gerindra: 20 calon perempuan, Partai PDI Perjuangan: 20 orang calon perempuan, Partai Golkar: 20 calon perempuan, Partai Nasdem: 19 calon perempuan, Partai Garuda: 8 calon perempuan, Partai Berkarya: 12 calon perempuan, PKS: 4 orang calon perempuan, Partai Perindo: 21 calon perempuan, PPP: 10 calon perempuan, PSI: 17 calon perempuan, PAN: 6 calon perempuan, Partai Hanura: 22 calon perempuan, Partai Demokrat: 21 calon perempuan, PBB: 1 calon perempuan, PKPI: 3 calon perempuan (dikutip dari www.bali.kpu.go.id). Fenomena politisi perempuan hanya untuk alat memenuhi kuota menyebabkan timbulnya kader-kader dadakan (Subiakto, Ida, 2014). Kondisi munculnya kader dadakan seperti inilah yang menyebabkan politisi perempuan Bali tidak bisa maju seperti kaum laki-laki. 
Kenyataannya di lapangan, politisi perempuan di Bali belum merepresentasikan kuota 30 persen. Banyak calon legislatif perempuan yang ikut dalam kontestasi politik, tetapi hanya sedikit yang berhasil terpilih untuk duduk di kursi legislatif daerah. Beberapa hal yang menyebabkan tidak banyak perempuan Bali yang mampu eksis layaknya laki-laki dalam politik, salah satunya terutama kualitas sumber daya manusia yaitu kemampuan/kecapakan politik yang tidak mumpuni yang tidak dimiliki oleh sebagian besar politisi perempuan. Eksistensi perempuan hanya dijadikan alat untuk memenuhi kuota partai politik agar lolos dalam seleksi Pemilu. Politisi perempuan Bali yang populer dan sudah duduk di kursi legislatif serta memangku jabatan kepala daerah dapat dihitung dengan jari seperti Sari Galung, Putu Metta, I Gusti Agung Putri Astrid, Ni Putu Eka Wiryastuti, dan I Gusti Ayu Mas Sumatri. Berkaca dari perempuanperempuan tersebut, maka penelitian ini hendak menjelaskan faktor utama yang menyebabkan para politisi perempuan tidak mampu bersaing, berkompetisi mendapatkan jabatan politik.

\section{KAJIAN PUSTAKA}

\section{Komunikasi Politik}

Menurut Dahlan (1999), komunikasi politik adalah suatu bidang disipilin ilmu yang mempelajari perilaku dan kegiatan komunikasi yang bersifat politik, mempunyai akibat politik, atau berpengaruh terhadap perilaku politik (Cangara, 2016). Menurut McNair (2003), political communication as pure discussion about the allocation of public resources (revenues), official authority (who is given the power to make legal, legislative and executive decision), and official sanctions (what the state reward or punishes) (Cangara, 2016). Jadi komunikasi politik menurut McNair adalah murni membicarakan tentang alokasi sumber daya publik yang memiliki nilai, apakah itu nilai kekuasaan atau nilai ekonomi, petugas yang memiliki kewenangan untuk memberikan kekuasaan dan keputusan dalam pembuatan undang-undang atau aturan, apakah itu legislatif atau eksekutif, serta sanksi-sanksi, apakah itu dalam bentuk hadiah atau denda (Cangara, 2016).

Salah satu unsur penting dalam komunikasi politik adalah komunikator politik. Komunikasi politik tidak hanya mengukur kualitas partai politik, melainkan juga lembaga pemerintahan legislatif dan eksekutif. Dengan demikian, sumber atau komunikator politik adalah mereka-mereka yang dapat memberi informasi tentang halhal yang mengandung makna atau bobot politik, misal Presiden, Menteri, anggota DPR, MPR, KPU, Gubernur, Bupati, Walikota, DPRD, politisi fungsionaris partai politik, fungsionaris Lembaga Swadaya Masyarakat (LSM), dan kelompok-kelompok penekan dalam masyarakat yang bisa mempengaruhi jalannya pemerintahan. Seorang komunikator politik harus memiliki kredibilitas yang tinggi, sehingga proses transfer ide, pesan politik, gagasan politik bisa tersampaikan secara mudah kepada masyarakat (Siagian, 2012:284). Sedangkan apabila seorang komunikator politik memiliki kredibilitas yang rendah, maka akan sulit mempertanggungjawabkan apa yang disampaikan, dan terjadi adalah kegagalan dalam komunikasi (Siagian, 2012:284) .

Dalam hal kredibilitas, ditekankan juga mengenai masalah profesionalisme yaitu kompetensi yang dimiliki seorang komunikator politik berdasarkan pengalaman/tidak berpengalaman, bergaya profesional/tidak bergaya profesional (Siagian, 2012:287). Unsur kemampuan komunikasi sangat dibutuhkan seorang 
komunikator politik dalam mempersuasi, memobilisasi massa, serta dalam melakukan lobi-lobi politik. Seorang komunikator politik memainkan peran yang sentral, khususnya dalam proses pembentukan opini publik. Oleh karena potensinya yang besar, maka seorang politisi harus mampu menganalisis situasi seperti pesan seperti apa yang akan disampaikan, melalui media atau saluran apa, penerima pesan siapa serta efek yang diharapkan timbul setelah melakukan kegiatan komunikasi politik. Menurut James Rossenau (dalam Slamet) ada tiga tipe komunikator politik, yaitu:

1. Komunikator yang menangani masalah nasional (Governmental Opinion Makers) atau disebut pembentuk opini pemerintah yang menangani masalah mengenai 'national multi issue matters' yaitu menangani berbagai masalah nasional atau berlevel nasional yang terdiri dari executive official yaitu para pejabat pemerintah dari mulai presiden sampai kabinet atau kementerian termasuk pimpinan departemen dengan seluruh jajarannya (eksekutif), kemudian jajaran legislatif (DPR) dan yudikatif sebagai badan peradilan.

2. Komunikator yang menangani masalah khusus yang disebut 'single issue opinion makers yaitu asisten atau sekretaris dan staf ahli dari departemen.

3. Komunikator pelaksana yaitu para pejabat yang berada di provinsi dan kabupaten/kotamadya yang akan merealisasikan dan meneruskan program pemerintah pusat sampai ke tingkat daerah.

\section{Budaya Politik}

Masyarakat Indonesia pada umumnya menganut budaya patrilineal dalam menjalani kehidupan sosial. Budaya patrilineal adalah budaya menempatkan kaum laki-laki lebih tinggi derajatnya dibanding kaum perempuan. Dalam sistem ini laki-laki dianggap kaum yang paling berkuasa dan perempuan hanya berada dibawah kontrol penuh laki-laki. Sistem ini dianggap tidak baik karena kondisi ini merembet hingga ke masalah pekerjaan, profesi atas dasar jenis kelamin bukan kemampuan riil si politisi perempuan. Menurut Murniati (dalam Mukarom, 2008:263), kelemahan perempuan akibat budaya patriarki adalah sebagai berikut:

a. Perempuan kurang menyadari bahwa dirinya adalah seorang pribadi yang mempunyai hak azasi manusia yang sama.

b. Perempuan seringkali kesulitan menghilangkan perasaan malu dan perasaan takut salah.

c. Perempuan kurang mampu berpikir jernih dan logis, sehingga sulit dalam mengambil keputusan.

d. Perempuan memiliki beban kerja domestik.

e. Perempuan selalu mempertimbangkan faktor keluarga, atau tradisi turun temurun keluarga yang aktif di organisasi.

f. Perempuan selalu mempertimbangkan faktor kesamaan agama.

g. Perempuan selalu mempertimbangakan faktor ekonomi.

h. Perempuan kurang dapat menerima kekuasaan (yang dipercayakan) dan dalam merebut kekuasaan lebih suka mengalah.

i. Perempuan kurang mampu mengendalikan emosi, sehingga pikirannya kurang stabil dan mudah terpengaruh.

j. Perempuan tidak mampu menjalin persatuan yang solid, sehingga mudah tercerai berai, dan sulit menyatukan pandangan. 
k. Perempuan kurang berminat untuk bekerja keras.

l. Perempuan lebih suka bergantung pada laki-laki daripada mandiri.

$\mathrm{m}$. Perempuan selalu mempertimbangkan dan tergantung pada kharisma pemimpin organisasi.

Atas dasar pertimbangan beberapa hal diatas, maka konsep budaya politik patrilineal tersebut sangat kental mempengaruhi eksistensi, motivasi, visi misi politisi perempuan untuk terjun dalam dunia politik. Karakteristik yang melekat pada perempuan dalam budaya patrilineal sangat menentukan arah serta gerak kerja kaum perempuan untuk bisa bersaing dengan pihak laki-laki.

\section{PEMBAHASAN}

Pemilu 2019 adalah ajang bagi para perempuan Bali untuk berkompetisi meraih simpati rakyat dalam meraih jabatan politik. Munculnya kuota 30 persen menyebabkan partai politik beramai-ramai mencari caleg perempuan, demi bisa lolos seleksi keikutsertaan dalam Pemilu. Menurut data LSM Bali Sruthi, jumlah caleg perempuan Bali yang ikut bertarung meraih posisi di DPRD Kota, DPRD Provinsi, dan DPR RI adalah 115 orang dari 16 partai politik (Rahayu dalam Putri, 2019) dalam www.bali.idntimes.com. Kenyataan yang terjadi lapangan adalah caleg perempuan tersebut hanya dijadikan alat untuk memenuhi kuota partai politik, dengan mengesampingkan kualitas yang dimiliki caleg perempuan itu sendiri. Hal ini berkaca dari pengalaman Pemilu-pemilu sebelumnhya, dimana jumlah perempuan yang mampu meraih jabatan politik di DPR RI tidak lebih dari 10 persen saja. Pada Pemilu 2014, dari total 415 kursi legislatif di Bali baik DPRD Kabupaten, Kota, dan Provinsi, jumlah perempuan yang terpilih hanya 4,5 persen yaitu 20 orang saja (Rahayu dalam Putri, 2019) dalam www.bali.idntimes.com. Dan kondisi ini sangat berbeda dengan provinsi-provinsi lain yang mampu meraup suara perempuan hingga 40 persen (Rahayu dalam Putri, 2019) dalam www.bali.idntimes.com.

Selain sebagai pelengkap untuk memenuhi kuota partai politik, perempuan Bali juga sering hanya dijadikan alat strategi politik oleh caleg para laki-laki agar partai yang mengusung mereka bisa lolos seleksi Pemilu dan mereka bisa melenggang dengan bebas meraup simpati masyarakat. Terkadang yang terjadi adalah partai politik seringkali memilih caleg perempuan yang belum siap untuk mencalonkan diri sebagai caleg, dipaksa diikutsertakan demi memenuhi kuota 30 persen. Munculnya caleg perempuan yang tidak siap ini, tentunya tidak mengancam suara para caleg laki-laki, dan apabila caleg perempuan yang direkrut ternyata memiliki kompetensi/kemampuan politik yang bagus biasanya dianggap batu ancaman bagi para caleg laki-laki terutama ketakutan apabila suara bisa hilang, teralihkan ke caleg perempuan yang kompeten tersebut.

Menurut Prof Henry Subiakto dan Prof Rachmah Ida, kelemahan yang dimiliki oleh politisi perempuan ketika bertarung dalam medan politik adalah masalah komunikasi politik. Menurut beliau perempuan lemah dalam hal 'komunikasi' dan 'lobilobi politik' (Subiakto, Ida, 2014). Sehingga hal tersebut memunculkan istilah 'kader dadakan' yaitu politisi yang dilahirkan tanpa memiliki kecakapan politik yang mumpuni (Subiakto, Ida, 2014). Sehingga yang terjadi adalah banyaknya caleg perempuan berasal dari dunia artis hingga caleg perempuan yang hanya bermodal materi, fisik saja tanpa diimbangi dengan modal kualitas ide/pemikiran yang cerdas. 
Seperti halnya di Bali, representasi perempuan yang mampu duduk sebagai anggota dewan dan kepala daerah masih sangat minim. Selain karena faktor kemampuan berpolitik yang belum maksimal, kemampuan para politisi perempuan tersebut juga masih sangat memprihatinkan. Para politisi perempuan masih sedikit yang vokal terhadap masalah politik, mereka ikut sebagai anggota partai hanya untuk adu gengsi/prestise di masyarakat, tanpa berpikir harus memiliki visi misi, motivasi kedepannya. Sebagai contoh, ketika diadakan acara simakrama ke banjar-banjar oleh seorang calon anggota dewan, peserta simakrama yang menunjukkan antusiasme hanya laki-lakinya (suami) saja. Si istri lebih memilih diam di rumah, cuek dan tidak peduli, serta selalu beralasan disibukkan oleh kegiatan upacara dsb. Dari sini terlihat bahwa perempuan Bali pada umumnya tidak terlalu antusias terhadap hal-hal berbau politik.

Masih rendahnya kualitas para politisi perempuan dalam kancah politik terlihat dari informasi yang didapatkan dari LSM Bali Sruthi, dimana LSM ini pada tahun 2009 aktif mendatangi partai politik untuk memberikan pelatihan bagi calon legislatif perempuan untuk meraih suara dan mengamankan suara (Rahayu dalam Putri, 2019) dalam www.bali.idntimes.com. Dari data yang diperoleh tingkat keterpilihan caleg perempuan mengalami peningkatan tahun 2009 sebesar 7,5 persen (Rahayu dalam Putri, 2019) dalam www.bali.idntimes.com. Namun menurut LSM Bali Sruthi tidak semua caleg perempuan minim pengetahuan dan kemampuan politik, ada juga caleg perempuan yang memang memulai karier politik dari nol dan mampu bersaing dengan caleg laki-laki. Indonesia adalah negara yang sedang berproses menuju demokrasi, dan salah satu tolak ukur keberhasilan demokrasi suatu negara adalah kemampuan mengakomodir dan menjamin bahwa hak-hak kaum perempuan dapat dilindungi.

Ada beberapa penyebab perempuan Bali kurang berkembang berkarier dalam dunia politik, pertama politisi perempuan Bali kurang memiliki kecapakan komunikasi dan lobi-lobi politik ketika masuk menjadi anggota partai politik. Kecakapan komunikasi harus diartikan luas, yaitu kemampuan si politisi perempuan untuk berbicara di depan publik, kemampuan mensosialisasikan program-program politik, kemampuan membangun jejaring politik/relasi politik serta kemampuan marketing politik. Salah satu contoh anggota legislatif DPRD Kota Denpasar Putu Metta yang mendapatkan suara terbanyak kedua di Dapil Denpasar Timur, strategi politik yang dia lakukan adalah menggunakan pendekatan sosial ke masyarakat seperti mendatangi Sekaa TerunaTeruni (STT), PKK, Keluarga, dan tetangga. Ada banyak cara yang bisa dilakukan dengan berkomunikasi menanyakan apa saja masalah yang perlu mendapatkan bantuan solusi dari pihak pemerintah daerah. Strategi tersebut ternyata lebih manjur untuk meraih simpati masyarakat tanpa perlu melakukan Money Politics.

Kedua, budaya politik patrilineal yang begitu kuat dalam masyarakat Bali sehingga perempuan seolah-olah hanya berkewajiban mengurusi urusan domestik/rumah tangga. Kondisi yang menempatkan kaum laki-laki diatas perempuan cenderung melahirkan marginalisasi kaum perempuan seperti (Scott dalam Zamroni, 2013:121):

a. Sebuah proses pengucilan (expulsion).

b. Sebuah proses penggeseran perempuan ke pinggiran (marginalization) dari pasar tenaga kerja.

c. Sebuah proses feminisasi atau segregasi. 
d. Sebuah proses ketimpangan ekonomi yang semakin meningkat.

Kondisi marginalisasi cukup terlihat pada kondisi yang dialami para caleg perempuan

di Bali, dimana caleg perempuan hanya dijadikan pelengkap untuk memenuhi kuota partai politik untuk dapat maju di Pemilu, sehingga hal tersebut mengesampingkan kualitas murni yang dimiliki kader perempuan tersebut. Diskriminasi kaum perempuan juga diperlihatkan oleh para caleg laki-laki yang secara sengaja mengajak kader perempuan yang memang belum siap untuk berkompetisi di dunia politik, sehingga para caleg laki-laki tersebut bebas tanpa ada kompetitor/pesaing dalam meraup suara pada Pemilu.

\section{KESIMPULAN}

Ada dua hal yang menyebabkan para caleg perempuan tidak mampu bersaing dalam kancah politik dengan laki-laki, pertama dikarenakan masalah kemampuan komunikasi politik yang masih tidak memadai khususnya kecakapan dalam komunikasi dan lobi-lobi politik yang harusnya sudah dimiliki oleh para caleg perempuan. Kedua, masalah budaya politik khususnya budaya patrilineal yang sangat kuat digunakan dalam masyarakat Bali, dan budaya patrilineal ini sudah merembet ke seluruh aspek kehidupan sosial di Bali, termasuk juga mempengaruhi peluang dan kesempatan bagi kaum perempuan untuk bisa berkiprah di dunia politik praktis.

\section{DAFTAR PUSTAKA}

Cangara, Hafied. 2016. Komunikasi Politik: Konsep, Teori, dan Strategi. Jakarta: PT Raja Grafindo Persada.

Gerintya, Scholastica. 2017. Kuota 30\% Perempuan di Parlemen Belum Pernah Tercapai (Online). Diakses di https://tirto.id/kuota-30-perempuan-di-parlemen-belum-pernahtercapai-cv8q (tanggal 8 Maret 2019).

KPU Provinsi Bali. 2018. Pengumuman Daftar Calon Tetap Anggota Dewan Perwakilan Rakyat Daerah (DPRD) Provinsi Bali (Online). Diakses di https://bali.kpu.go.id/bacapengumuman/157/PENGUMUMAN-DAFTAR-CALON-TETAP-ANGGOTA-DEWANPERWAKILAN-RAKYAT-DAERAH-awaIDPRDakhir-PROVINSI-BALI (tanggal 9 Maret 2019).

Mukarom, Zaenal. 2008. Perempuan dan Politik: Studi Komunikasi Politik tentang Keterwakilan Perempuan di Legislatif (Online). Mediator, Vol. 9, No. 2, Desember 2008. Diakses di https://ejournal.unisba.ac.id/index.php/mediator/article/viewFile/1125/681 (tanggal 8 Maret 2019).

Putri, Diantari. 2019. Perempuan Bali yang Tak Siap Nyaleg 'Diburu' Untuk Penuhi Kuota Partai (Online). Diakses di https://bali.idntimes.com/news/bali/diantari-putri/perempuan-baliyang-tak-siap-nyaleg-diburu-untuk-penuhi-kuota-partai-1/full (tanggal 8 Maret 2019).

Siagian, Haidir Fitra. 2012. Pengaruh Kredibilitas Komunikator Politik untuk Mendapatkan Dukungan Khalayak dalam Pemilihan Umum (Online). Jurnal Dakwah Tabligh, Vol. 13, No. 2, Desember 2012. Diakses di https://media.neliti.com/media/publications/76108-ID-pengaruh-kredibilitaskomunikator-politi.pdf (tanggal 8 Maret 2019). 
Slamet, Adiyana. Karakteristik Komunikator Politik (Online). Diakses di https://repository.unikom.ac.id/35507/1/Karakteristik\%20Komunikator\%20politik\%20 5 .pdf (tanggal 9 Maret 2019).

Subiakto, Henry dan Rachmah Ida. 2014. Komunikasi Politik, Media, dan Demokrasi. Jakarta: Prenada.

Zamroni, Mohammad. 2013. Perempuan dalam Kajian Komunikasi Politik dan Gender (Online). Jurnal Dakwah, Vol. XIV, No. 1 Tahun 2013. Diakses di https://media.neliti.com/media/publications/77701-ID-perempuan-dalam-kajiankomunikasi-politi.pdf (tanggal 9 Maret 2019). 
